\title{
Suppression of Leakage Current and Distortion in Variable Capacitance Devices and their Application to AC Power Regulators
}

\author{
Akihiko Katsuki ${ }^{\dagger}$ and Takuya Oki ${ }^{*}$ \\ ${ }^{\dagger}$ Next Generation Switching Power Course, Nagasaki University, Nagasaki, Japan \\ *Department of Computer Science and Electronics, Kyushu Institute of Technology, Iizuka-shi, Fukuoka, Japan
}

\begin{abstract}
The quantity of alternating current (AC) leakage and the value of distortion factor in capacitor currents are discussed with regard to a new power component called variable capacitance device (VCD). This component has terminals for controlling its capacitance. Nonlinear dielectric characteristics are utilized in this device to vary the capacitance. When VCD operates in an AC circuit, the AC leakage from this device through direct current (DC) control voltage source increases according to the conditions of DC control voltage and so on. To solve this problem, we propose techniques for suppressing AC leakage. Although VCD has strong nonlinear characteristics, the current through the capacitor is not distorted significantly. The relations between AC leakage and the distortion in current waveforms are investigated. An application example for an AC power regulator is also introduced to evaluate the distortion in waveforms.
\end{abstract}

Key words: AC power regulator, Current distortion, DC control voltage, Leakage current, Variable capacitance device

\section{INTRODUCTION}

If power devices of variable capacitance can be used, then many applications will be possible in the field of power electronics. In alternating current (AC) voltage regulators, such as ferroresonant circuit, inductances are usually varied to control output voltage. A simulated saturating reactor [1] is assembled by a small inductor and semiconductor switches. A voltage regulator with this circuit has a reduced size and weight in comparison with a ferroresonant transformer [2]. However, considerable magnetic fields are generated, thereby causing electronic equipment to malfunction. This condition is not desirable for a clean and safe environment.

Varactors are passive components that can vary their capacitance. However, they have a small operating current (e.g., less than approximately $10 \mu \mathrm{A}$ ) because they are basically reverse-biased diodes. Therefore, their application is

Manuscript received Dec. 21, 2014; accepted Jul. 30, 2015

Recommended for publication by Associate Editor Honnyong Cha.

†Corresponding Author: katsuki@nagasaki-u.ac.jp

Tel: +81-95-819-2692, Fax: +81-95-819-2692, Nagasaki University

* Department of Computer Science and Electronics, Kyushu Institute of

Technology, Japan limited to small signal use.

Variable capacitance device (VCD) [3], [4] is proposed on the supposition that the value of an operating current is several amperes or more. This device is realized by using the capacitance varying characteristics of direct current (DC) bias voltage across a ceramic capacitor [5]-[7].

A ceramic capacitor has nonlinearity in the characteristics between dielectric constant and electric field, that is, those between capacitance and DC bias voltage. Ceramic capacitors are usually used in the circuit with a fixed DC bias voltage to avoid this influence. However, the influence of nonlinearity on the use of such capacitors in AC circuits cannot be neglected.

In this study, the major problems on the use of ceramic capacitors in AC circuits, that is, AC leakage from VCD to DC controlling voltage source, and waveform distortion are investigated in detail. Leakage current suppression techniques can be applied to AC power regulators. With respect to an $\mathrm{AC}$ power regulator with constant voltage/constant current (CV/CC), the relationship between AC leakage suppression technique and waveform distortion is reported, including the observed waveforms and measured data on efficiency. 


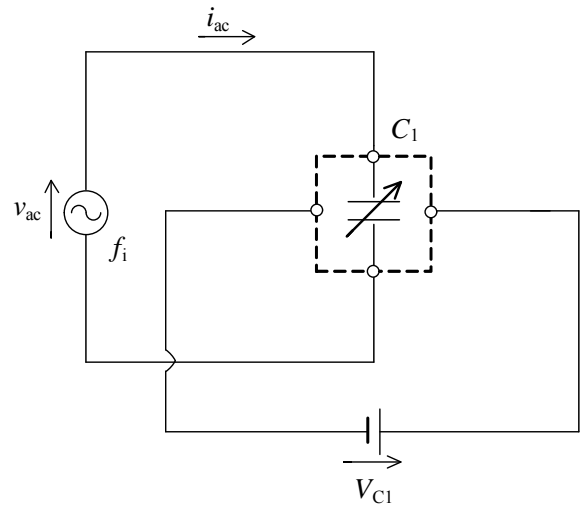

Fig. 1. VCD.

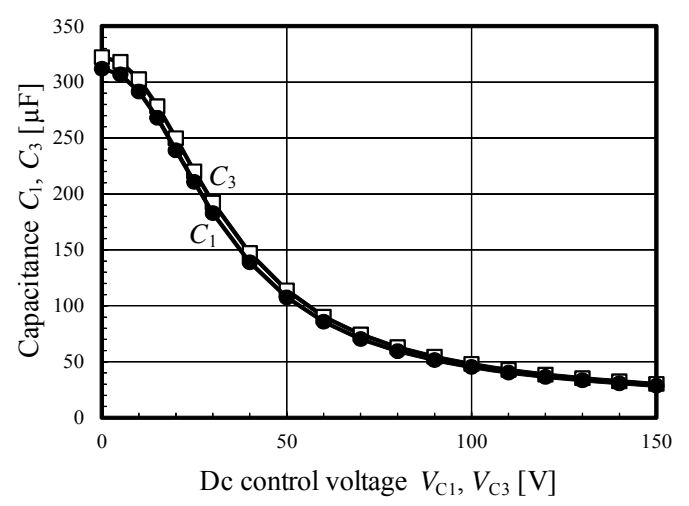

Fig. 2. Example of measured control characteristics in VCDs.

\section{VCD}

We introduce the use of VCD in an AC circuit. The circuit symbol of VCD is depicted in Fig. 1. Fig. 2 presents an example of the measured data between capacitance $C_{1}$ and DC control voltage $V_{\mathrm{Cl}}$, in which the $\mathrm{AC}$ current for measurement is sufficiently small. Fig. 2 shows that the capacitances can be adjusted by changing DC control voltage.

The structure of a four-terminal VCD is depicted in Fig. 3. Four capacitors $C_{A}, C_{B}, C_{C}$, and $C_{D}$ have the same characteristics. With the use of two resistors $\mathrm{R}_{\mathrm{B}}$, the same DC voltages are imposed on the four capacitors.

\section{LEAKAGE CURRENT SUPPRESSION}

In Fig. 3, the voltages $v_{\mathrm{A}}, v_{\mathrm{B}}, v_{\mathrm{C}}$, and $v_{\mathrm{D}}$ across the capacitors $\mathrm{C}_{\mathrm{A}}, \mathrm{C}_{\mathrm{B}}, \mathrm{C}_{\mathrm{C}}$, and $\mathrm{C}_{\mathrm{D}}$ can be expressed by $V_{\mathrm{C} 1}$ and the $\mathrm{AC}$ voltage $v_{\mathrm{ac}}$ as follows:

$$
\begin{aligned}
& v_{\mathrm{A}}=v_{\mathrm{D}}=\frac{V_{\mathrm{C} 1}+v_{\mathrm{ac}}}{2} \\
& v_{\mathrm{B}}=v_{\mathrm{C}}=\frac{V_{\mathrm{C} 1}-v_{\mathrm{ac}}}{2}
\end{aligned}
$$

The DC control voltage source $\mathrm{V}_{\mathrm{C} 1}$ has low impedance against AC. In this study, its impedance is assumed to be zero.

The bridge connection of the four well-balanced capacitors reduces the AC leakage $i_{\mathrm{c}}$ considerably through DC control

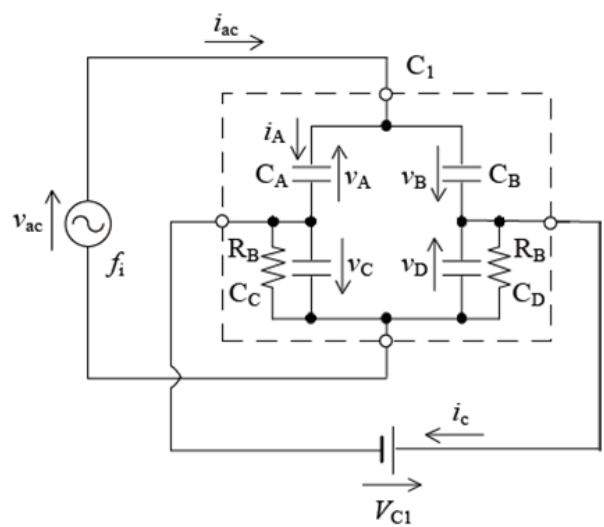

Fig. 3. Structure of a VCD.

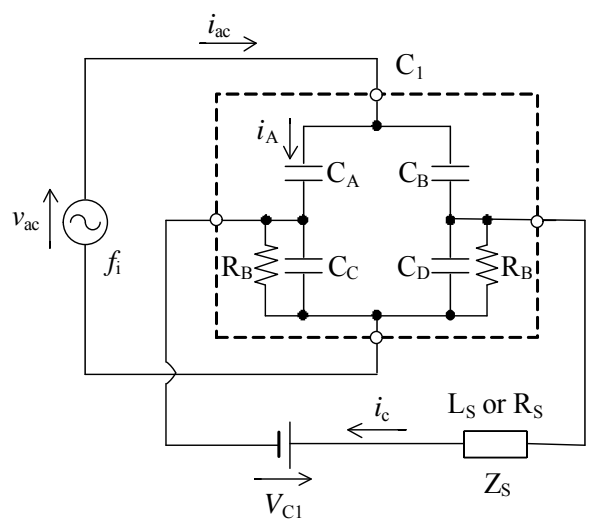

Fig. 4. Leakage current suppression in the VCD.

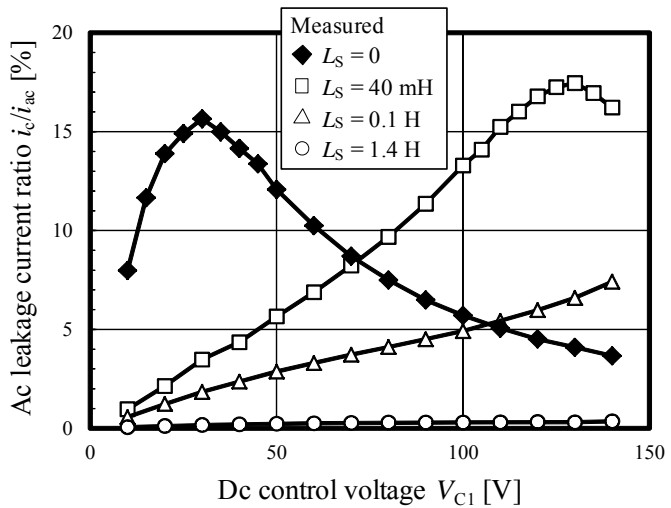

Fig. 5. Measured data on the AC leakage ratio $i_{\mathrm{c}} / i_{\mathrm{ac}}$ vs. the DC control voltage $V_{\mathrm{C} 1}$ characteristics having the inductor $\mathrm{L}_{\mathrm{S}}$ as series impedance device $Z_{S}$.

loop when $V_{\mathrm{C} 1}$ is higher than the AC voltage $v_{\mathrm{ac}}$. However, an impedance device $Z_{s}$ needs to be inserted to suppress $A C$ leakage, as shown in Fig. 4, when the AC voltage $v_{\text {ac }}$ becomes high.

Figs. 5 and 6 show data on the AC leakage $i_{\mathrm{c}}$ from the VCD $\mathrm{C}_{1}$ to the $\mathrm{DC}$ control voltage source $\mathrm{V}_{\mathrm{Cl}}$. The current $i_{\mathrm{ac}}$ is the total $\mathrm{AC}$ current. These graphs depict the ratio $i_{\mathrm{c}} / i_{\mathrm{ac}}$. In this study, $v_{\mathrm{ac}}$ is sinusoidal. Its frequency $f_{\mathrm{i}}$ and amplitude equal $60 \mathrm{~Hz}$ and $10 \mathrm{~V}$, respectively.

As reference, the graph $L_{\mathrm{S}}=0$ in Fig. 5 or the graph $R_{\mathrm{S}}=0$ in Fig. 6 presents the data without $Z_{S}$. When $V_{\mathrm{C} 1}$ is 


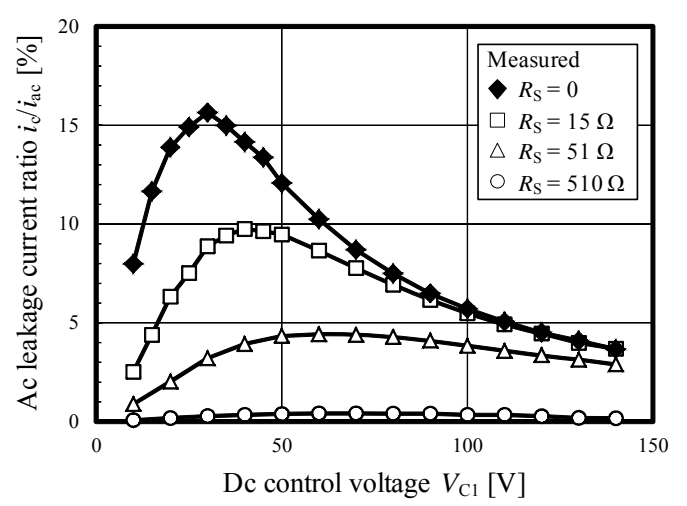

Fig. 6. Measured data on the AC leakage ratio $i_{\mathrm{c}} / i_{\mathrm{ac}}$ vs. the DC control voltage $V_{\mathrm{C} 1}$ characteristics having the resistor $\mathrm{R}_{\mathrm{S}}$ as series impedance device $Z_{S}$.

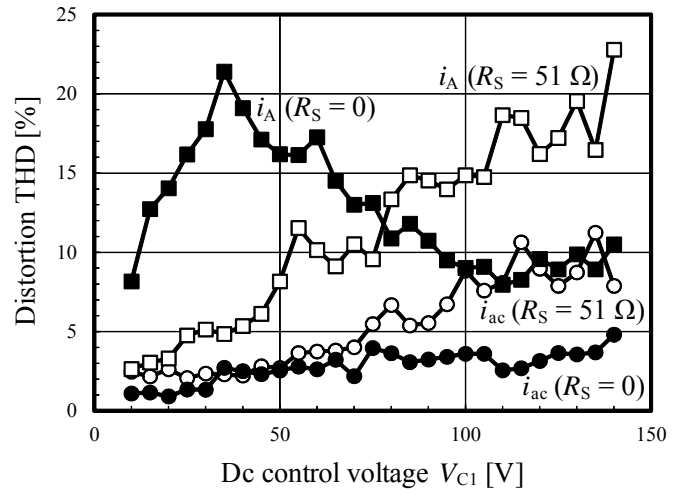

Fig. 7. Measured characteristics on the THD of the currents $i_{\mathrm{A}}$ and $i_{\mathrm{ac}}$ with the resistance $R_{\mathrm{S}}$ as parameter.

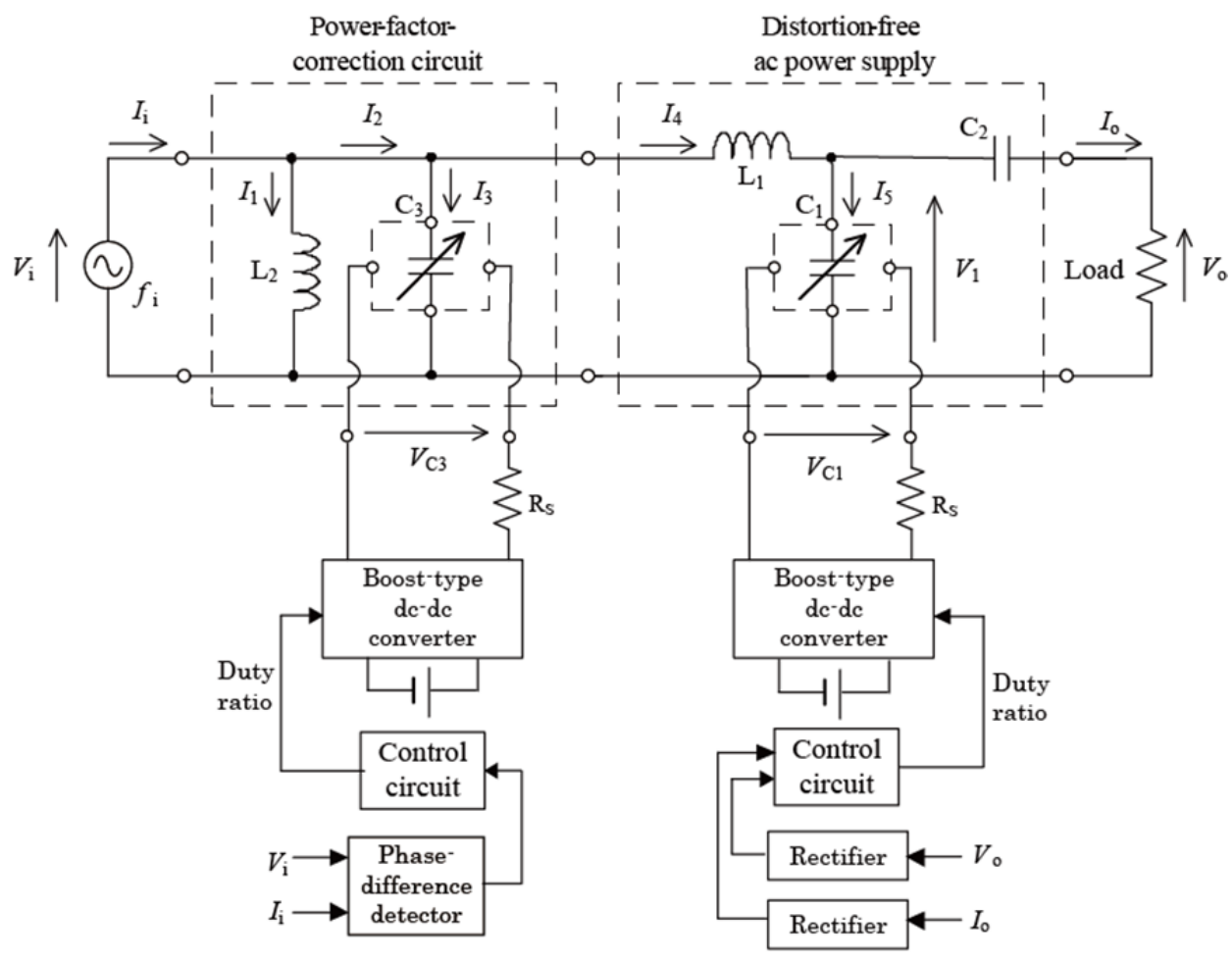

Fig. 8. PFC CV/CC AC power regulator by the use of VCDs.

approximately $30 \mathrm{~V}$, the ratio $i_{\mathrm{c}} / i_{\mathrm{ac}}$ has a maximum value. This condition corresponds to the maximum declivity in Fig. 2.

In Fig. 5, the inductor $\mathrm{L}_{\mathrm{S}}$ is used as a series impedance device. Under a low $V_{\mathrm{C} 1}$, an inductor with relatively small inductance will be applicable.

The series component in Fig. 6 is the resistor $\mathrm{R}_{\mathrm{S}}$. Even if $R_{\mathrm{S}}$ is low, usage with a relatively high $V_{\mathrm{C} 1}$ leads to good reduction characteristics on $i_{\mathrm{c}} / i_{\mathrm{ac}}$. A $51 \Omega$ resistor is used below for the impedance device $Z_{S}$ in consideration of cost, size, and weight.

\section{SUPPRESSION OF DISTORTION}

For example, the capacitance $C_{\mathrm{A}}$ is a function of the voltage $v_{\mathrm{A}}$. Given that $v_{\mathrm{A}}$ varies with the time $t, C_{\mathrm{A}}$ becomes a time-variant parameter. In this case, with respect to the capacitor $\mathrm{C}_{\mathrm{A}}$, the following relations are valid:

$$
\begin{gathered}
i_{\mathrm{A}}=\frac{d}{d t}\left(C_{\mathrm{A}} v_{\mathrm{A}}\right) \\
i_{\mathrm{A}}=C_{\mathrm{A}} \frac{d v_{\mathrm{A}}}{d t}+v_{\mathrm{A}} \frac{d C_{\mathrm{A}}}{d t}
\end{gathered}
$$

The second term in the right part of Equ. (4) provides the information on distortion.

Fig. 7 shows the measured characteristics on total harmonic distortion (THD) with respect to the capacitor currents $i_{\mathrm{ac}}$ and $i_{\mathrm{A}}$. From Fig. 4, $i_{\mathrm{A}}$ means the current that flows through the capacitor $\mathrm{C}_{\mathrm{A}}$. The amplitude of $v_{\mathrm{ac}}$ is set to $10 \mathrm{~V}$. The THD of $v_{\mathrm{ac}}$ is approximately $0.17 \%$, which is smaller than that of $i_{\mathrm{ac}}$ or $i_{\mathrm{A}}$. In both cases of $R_{\mathrm{S}}=0$ and $R_{\mathrm{S}}=$ $51 \Omega$, the distortion in $i_{\mathrm{ac}}$ becomes smaller than that in $i_{\mathrm{A}}$. The 


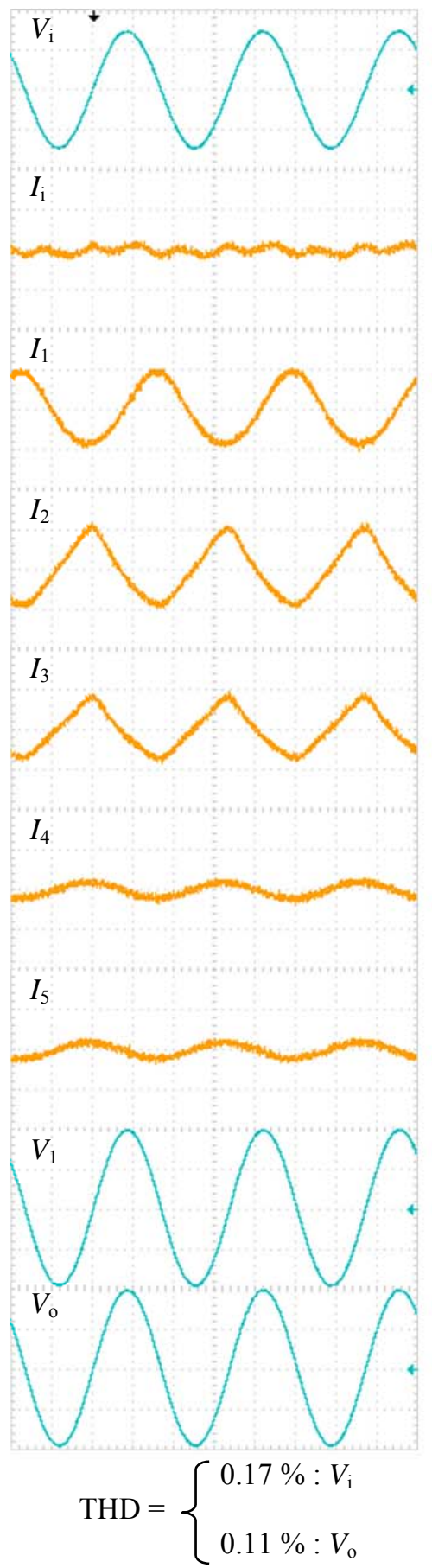

(a)

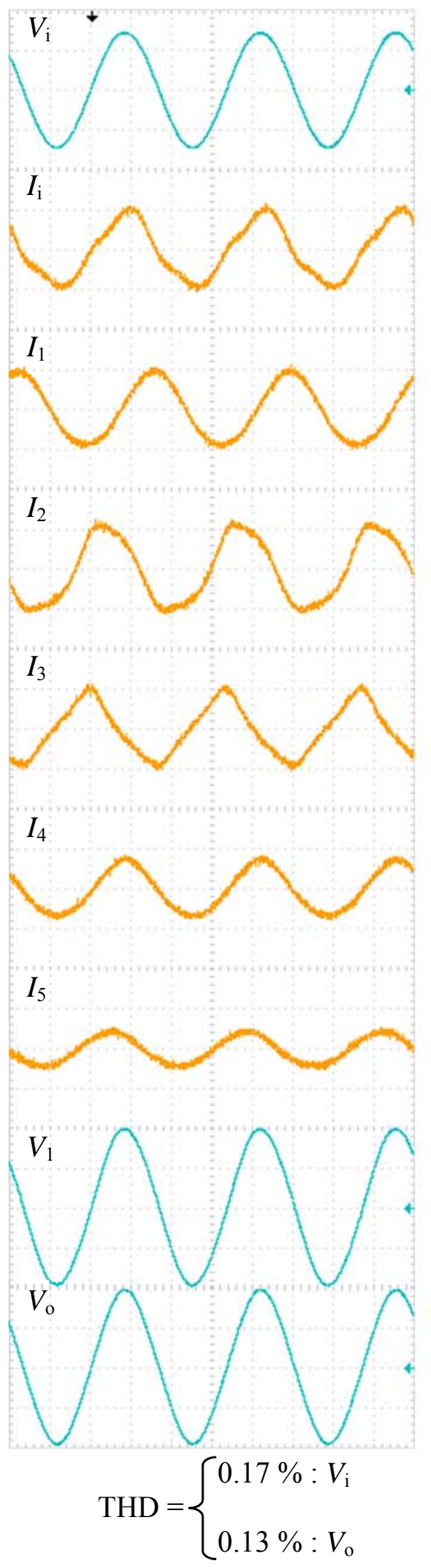

(b)

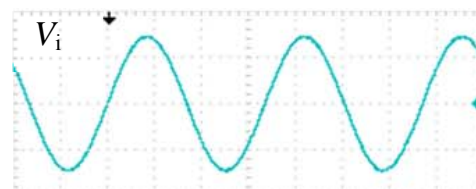

$I_{\mathrm{i}}$
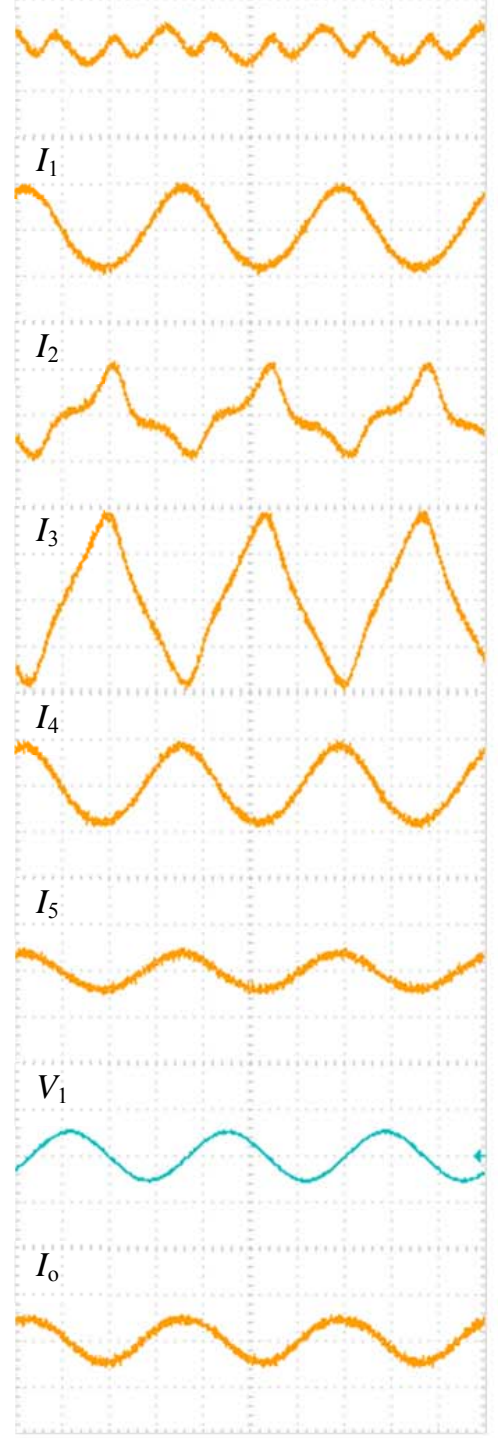

$\mathrm{THD}=\left\{\begin{array}{l}0.18 \%: V_{\mathrm{i}} \\ 1.67 \%: I_{\mathrm{o}}\end{array}\right.$

(c)

Fig. 9. Observed waveforms with the VCDs $\mathrm{C}_{1}, \mathrm{C}_{3}$, the sinusoidal input voltage $V_{\mathrm{i}}$, and $R_{\mathrm{S}}=51 \Omega$, where $V_{\mathrm{i}}=21 \mathrm{~V}$; vertical: $20 \mathrm{~V} / \mathrm{div}$ for $V_{\mathrm{i}}, V_{1}$, and $V_{\mathrm{o}}, 2 \mathrm{~A} / \mathrm{div}$ for $I_{\mathrm{i}}, I_{1}-I_{5}$, and $I_{\mathrm{o}}$; horizontal: $5 \mathrm{~ms} / \mathrm{div}$ : (a) $I_{\mathrm{o}}=0$ and $V_{\mathrm{o}}=28 \mathrm{~V}$ (no load), (b) $I_{\mathrm{o}}=0.81 \mathrm{~A}$ and $V_{\mathrm{o}}=28 \mathrm{~V}$ (full load), and (c) $I_{\mathrm{o}}=0.81 \mathrm{~A}$ and $V_{\mathrm{o}}=0$ (short-circuit load).

distortion in $i_{\mathrm{ac}}$ can be negligibly small particularly under the condition of $R_{\mathrm{S}}=0$. In this case, $\mathrm{C}_{\mathrm{A}}$ and $\mathrm{C}_{\mathrm{B}}$ and $\mathrm{C}_{\mathrm{C}}$ and $\mathrm{C}_{\mathrm{D}}$ are paralleled. The influence of nonlinearity can be compensated effectively. Even if $R_{\mathrm{S}}=51 \Omega$, the total current $i_{\mathrm{ac}}$ becomes near sinusoidal.

\section{EVALUATION OF THE DisTORTION IN AN AC POWER REGULATOR}

Fig. 8 presents a $\mathrm{CV} / \mathrm{CC} \mathrm{AC}$ power regulator with input power factor correction (PFC) [8] as example of the 


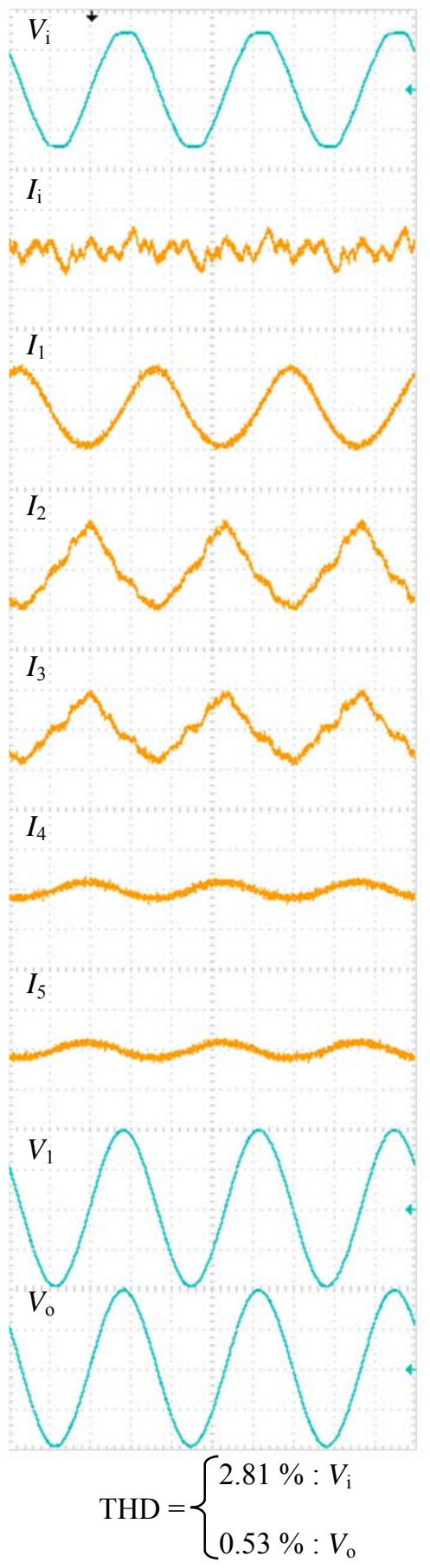

(a)

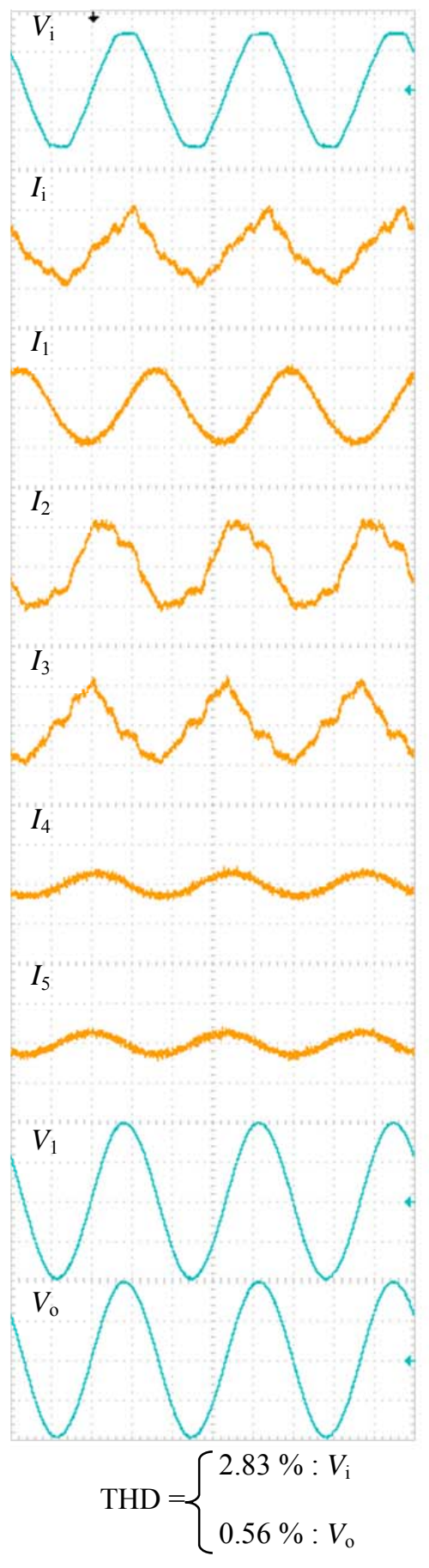

(b)

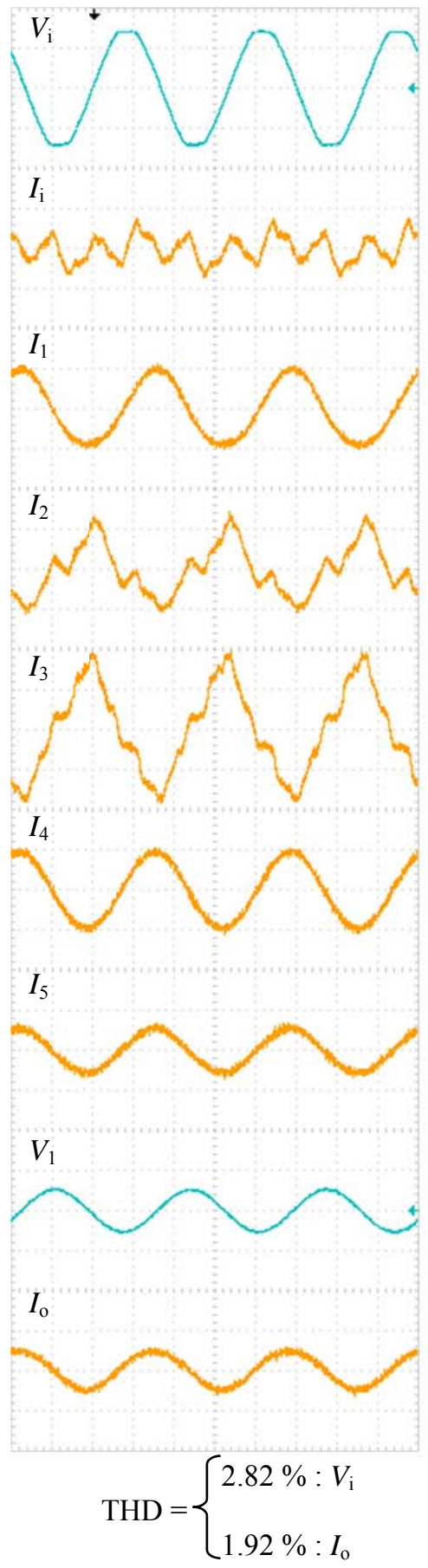

(c)

Fig. 10. Observed waveforms with the VCDs $\mathrm{C}_{1}, \mathrm{C}_{3}$, the commercial AC input voltage $V_{\mathrm{i}}$, and $R_{\mathrm{S}}=51 \Omega$. The others are the same as in Fig. 9.

application of VCDs. In this study, the capacitances $C_{1}$ and $C_{3}$ are variable. Load is assumed to be resistive.

The simplified block diagram for control circuit is also included in Fig. 8. Two boost-type DC-DC converters are utilized in this study for the high-speed drivers of two VCDs.
In the experimental circuit, the constant output voltage $V_{\mathrm{o}}$ $=28 \mathrm{~V}$ or the constant output current $I_{\mathrm{o}}=0.81 \mathrm{~A}$ can be obtained against the input voltage $V_{\mathrm{i}}=18-24 \mathrm{~V}$. For the VCDs $C_{1}$ and $C_{3}$, the measured data on capacitance against DC control voltage are shown in Fig. 2. 


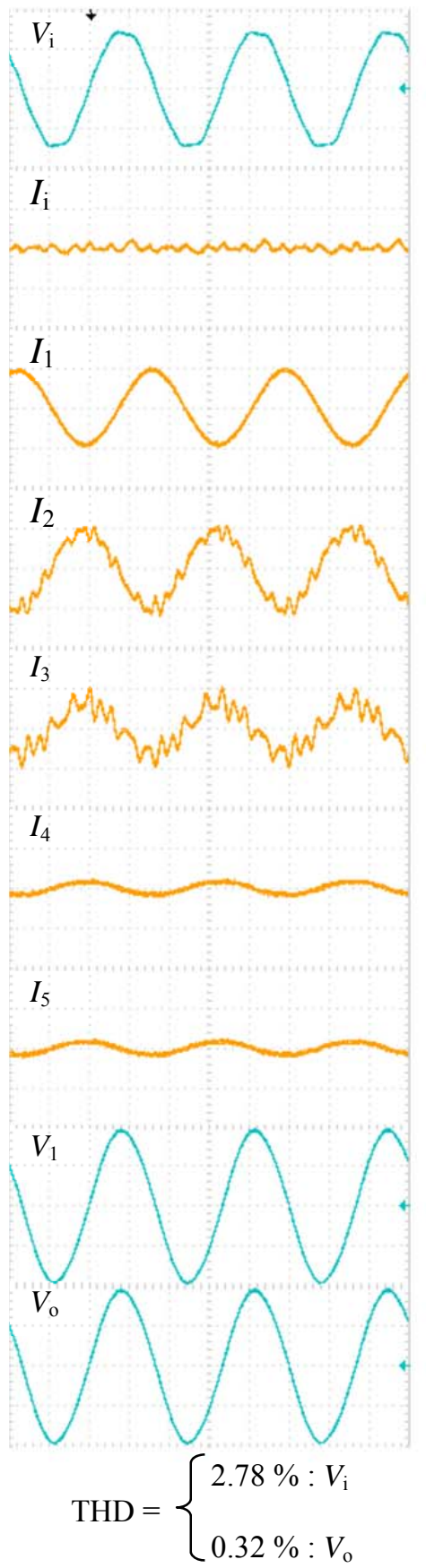

(a)

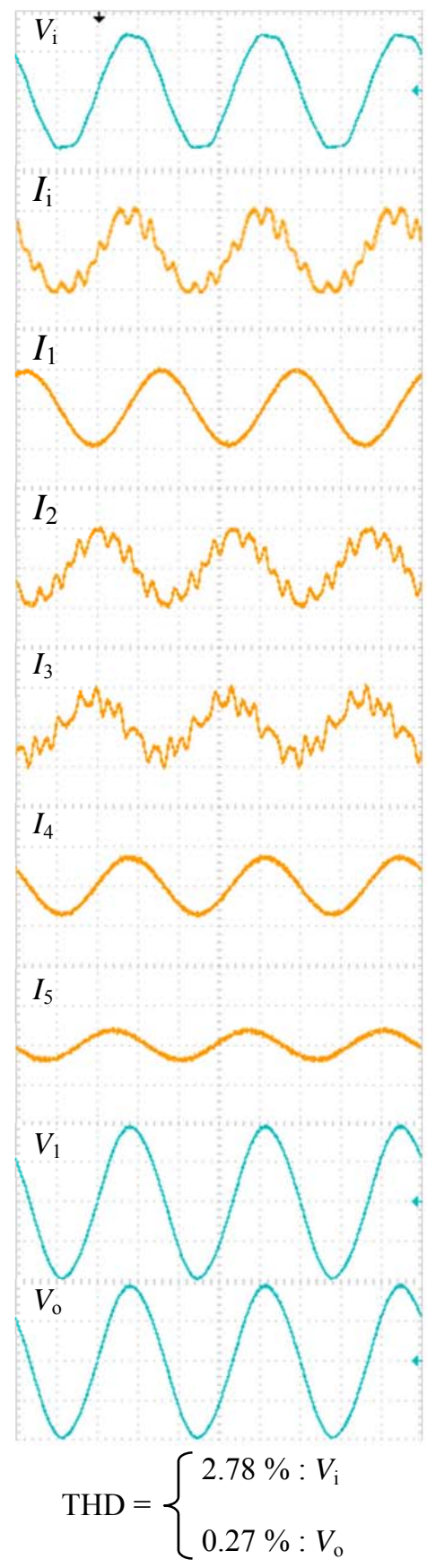

(b)

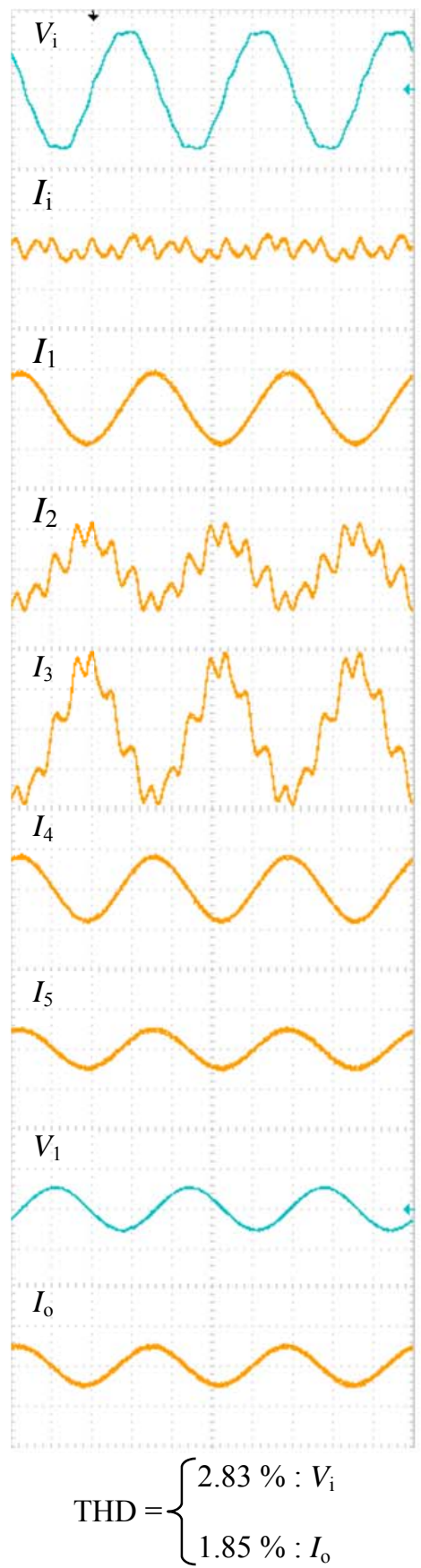

(c)

Fig. 11. Observed waveforms with the film capacitors $\mathrm{C}_{1}, \mathrm{C}_{3}$ and the commercial AC input voltage $V_{\mathrm{i}}$ as reference. The others are the same as in Fig. 9.

The conditions are as follows: inductance of $\mathrm{L}_{1}, L_{1}=$ $58 \mathrm{mH}$, loss resistance of $\mathrm{L}_{1}, r_{1}=0.6 \Omega$, inductance of $\mathrm{L}_{2}, L_{2}$ $=35 \mathrm{mH}$, loss resistance of $\mathrm{L}_{2}, r_{2}=0.2 \Omega$, and capacitance of $\mathrm{C}_{2}, C_{2}=290 \mu \mathrm{F}$.

Figs. 9-11 show the observed waveforms, where $V_{\mathrm{i}}, V_{\mathrm{o}}, I_{\mathrm{i}}$, and $I_{0}$ are the input voltage, the output voltage, the input current, and the output current, respectively. With respect to
$V_{\mathrm{i}}$, amplified sinusoidal voltage is used in Fig. 9. By contrast, $V_{\mathrm{i}}$ is furnished by a commercial AC in our laboratory for Figs. 10 and 11 . In Figs. 9 and $10, R_{\mathrm{S}}$ is equal to $51 \Omega$.

Fig. 9 presents the distortions generated when the input is a sinusoidal wave. A comparison between Figs. 9 and 10 implies that the THD of $V_{\mathrm{o}}$ or $I_{\mathrm{o}}$ does not gain much even if $V_{\mathrm{i}}$ is distorted. The high harmonic components in input voltage 


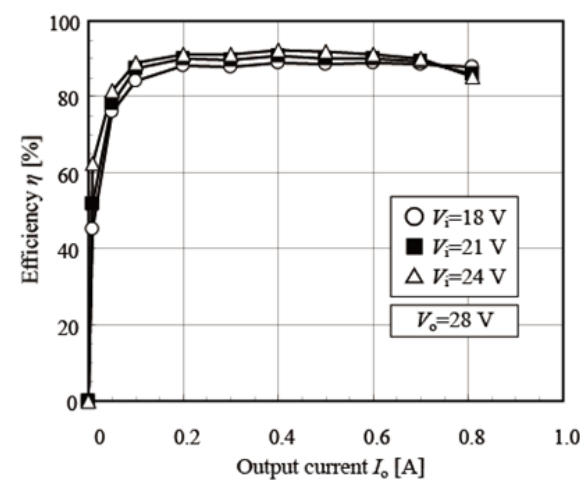

(a)

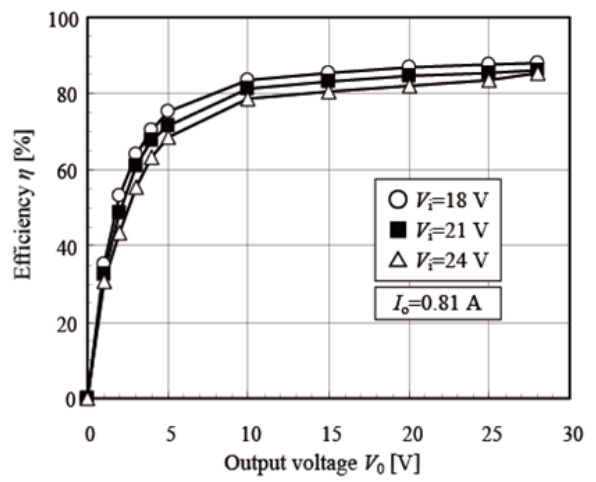

(b)

Fig. 12. Measured data of efficiency $\eta$ with the $V C D s C_{1}$ and $C_{3}$ : (a) $\mathrm{CV}$ region and (b) $\mathrm{CC}$ region.

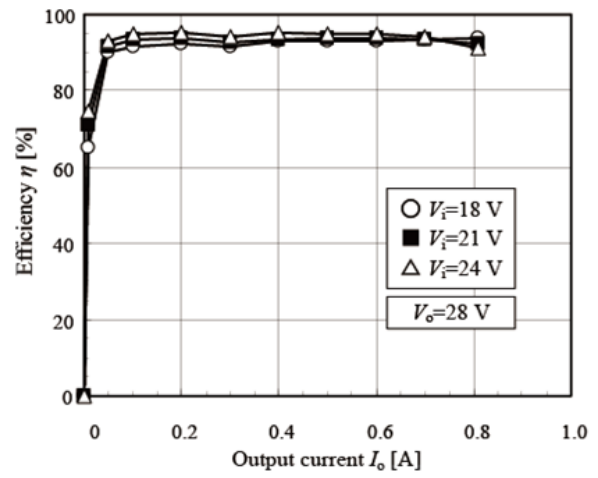

(a)

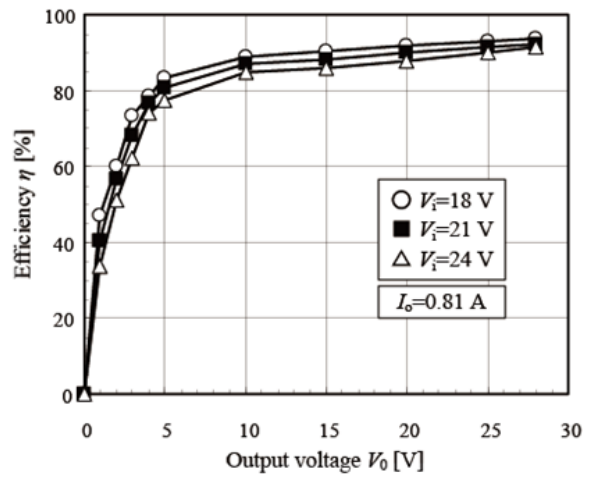

(b)

Fig. 13. Measured data of efficiency $\eta$ with the film capacitors $\mathrm{C}_{1}$ and $\mathrm{C}_{3}$ as reference: (a) $\mathrm{CV}$ region and (b) $\mathrm{CC}$ region. are effectively reduced.

As reference, Fig. 11 shows the observed waveforms using film capacitors of the same capacitance with VCDs. In this case, the included distortion is not derived from the VCDs. We suppose that the distortion is caused by magnetic devices and the high harmonic components of the commercial AC.

The measured values on THD are as follows:

(1) VCDs, sinusoidal AC input, and $R_{\mathrm{S}}=51 \Omega$ (see Fig. 9).

(a) No load; $V_{\mathrm{i}}: 0.17 \%, V_{\mathrm{o}}: 0.11 \%$.

(b) Full load; $V_{\mathrm{i}}: 0.17 \%, V_{\mathrm{o}}: 0.13 \%$.

(c) Short-circuit load; $V_{\mathrm{i}}: 0.18 \%, I_{\mathrm{o}}: 1.67 \%$.

(2) VCDs, sinusoidal AC input, and $R_{\mathrm{S}}=0$.

(a) No load; $V_{\mathrm{i}}: 0.18 \%, V_{\mathrm{o}}: 0.10 \%$.

(b) Full load; $V_{\mathrm{i}}: 0.19 \%, V_{\mathrm{o}}: 0.11 \%$.

(c) Short-circuit load; $V_{\mathrm{i}}: 0.17 \%, I_{\mathrm{o}}: 1.53 \%$.

(3) Film capacitors and sinusoidal AC input.

(a) No load; $V_{\mathrm{i}}: 0.18 \%, V_{\mathrm{o}}: 0.09 \%$.

(b) Full load; $V_{\mathrm{i}}: 0.19 \%, V_{\mathrm{o}}: 0.10 \%$.

(c) Short-circuit load; $V_{\mathrm{i}}: 0.17 \%, I_{\mathrm{o}}: 1.45 \%$.

(4) VCDs, commercial AC input, and $R_{\mathrm{S}}=51 \Omega$ (see Fig. 10).

(a) No load; $V_{\mathrm{i}}: 2.81 \%, V_{\mathrm{o}}: 0.53 \%$.

(b) Full load; $V_{\mathrm{i}}: 2.83 \%, V_{\mathrm{o}}: 0.56 \%$.

(c) Short-circuit load; $V_{\mathrm{i}}: 2.82 \%, I_{\mathrm{o}}: 1.92 \%$.

(5) VCDs, commercial AC input, and $R_{\mathrm{S}}=0$.

(a) No load; $V_{\mathrm{i}}: 2.77 \%, V_{\mathrm{o}}: 0.34 \%$.

(b) Full load; $V_{\mathrm{i}}: 2.76 \%, V_{\mathrm{o}}: 0.33 \%$.

(c) Short-circuit load; $V_{\mathrm{i}}: 2.84 \%, I_{\mathrm{o}}: 1.87 \%$.

(6) Film capacitors and commercial AC input (see Fig. 11).

(a) No load; $V_{\mathrm{i}}: 2.78 \%, V_{\mathrm{o}}: 0.32 \%$.

(b) Full load; $V_{\mathrm{i}}: 2.78 \%, V_{\mathrm{o}}: 0.27 \%$.

(c) Short-circuit load; $V_{\mathrm{i}}: 2.83 \%, I_{\mathrm{o}}: 1.85 \%$.

The data indicate that the distortion caused by VCDs is insignificant at $R_{\mathrm{S}}=51 \Omega$ and $R_{\mathrm{S}}=0$.

Finally, the measured data on efficiency with VCDs and film capacitors are given in Figs. 12 and 13, respectively. In Fig. 13, VCDs are replaced with film capacitors of the same capacitance. The power loss in VCD is small.

\section{CONCLUSION}

Inserting a suitable small-resistance resistor between the VCD and the DC control voltage source is effective for leakage current suppression. This resistor has almost no influence on capacitor current distortion.

Although the proposed VCD is made by using strong nonlinear characteristics, the waveform of the total current is not distorted considerably. The low distortion is due to the effective canceling of the high harmonic components by the internal currents in VCD.

In the proposed AC regulator for application in VCD, the distortion in input voltage is reduced by the effect of circuit configuration. Even if the AC input is a distorted voltage, such as the commercial AC voltage, the output waveform becomes close to a sinusoidal wave. 


\section{REFERENCES}

[1] R. J. Kakalec, "A feedback-controlled ferroresonant voltage regulator," IEEE Trans. Magn., Vol. 6, No. 1, pp. 4-8, Mar. 1970.

[2] R. N. Basu, "A new approach in the analysis and design of a ferroresonant transformer," IEEE Trans. Magn., Vol. 3, No. 1, pp. 43-49, Mar. 1967.

[3] A. Katsuki, K. Shirouzu, K. Harada, and M. Fujiwara, "Improved variable capacitance device and its applications to resonant converters," in $15^{\text {th }}$ Int. Telecommunications Energy Conf.(INTELEC), Vol. 2, pp. 242-246, Sep. 1993.

[4] K. Harada, A. Katsuki, M. Fujiwara, H. Nakajima, and H. Matsushita, "Resonant converter controlled by Variable Capacitance Devices," IEEE Trans. Power Electron., Vol. 8, No. 4, pp. 404-410, Oct. 1993.

[5] S. Igarashi, Multi-layered Ceramic Capacitors, Gakken-sha, 1988.

[6] M. W. Barsoum, Fundamentals of Ceramics, McGraw-Hill, 1997.

[7] S. O. Kasap, Principles of Electrical Engineering Materials and Devices, Rev., McGraw-Hill, 2000.

[8] A. Katsuki, K. Yoshimatsu, H. Tanoue, and Y. Sugimoto, "Distortion-free CV/CC AC power supply having the unity input power factor by the use of Variable Capacitance Devices," International Journal of Renewable Energy Research, Vol. 4, No. 3, pp. 641-646, Sep. 2014.

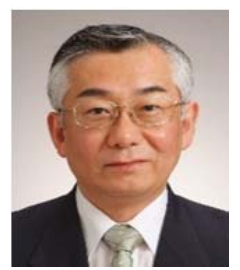

Akihiko Katsuki was born in Fukuoka, Japan in 1956. He received his B.Eng., M.Eng., and Ph.D. degrees from Kyushu University, Fukuoka, Japan in 1978, 1980, and 1983, respectively. In 1983, he was a research associate at Kyushu University. From 1988 to 1990, he was an associate professor at Kyushu University. In 1990, he was an associate professor at the Kyushu Institute of Technology, Fukuoka, Japan. Since 2013, he has been a professor at Nagasaki University, Nagasaki, Japan. His research interests include nonlinear power magnetics, power electronics, and communication circuits.

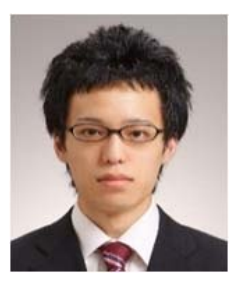

Takuya Oki was born in Hiroshima, Japan in 1988. He received his B.Eng. and M.Eng. degrees in Computer Science and Systems Engineering from Kyushu Institute of Technology, Iizuka, Fukuoka, Japan in 2010 and 2012, respectively. Since April 2012, he has been with Shindengen Electric Manufacturing Co., Japan. His current research interest is power electronics. 